\title{
Demographic and histological subtypes of Hurthle cell tumours of the thyroid in a South African setting
}

\author{
V Malith, ${ }^{1,2}$ I Bombil, $, 1,2,4$ N Harran, ${ }^{4}$ TE Luvhengo ${ }^{1,3,4}$ \\ ${ }^{1}$ Department of Surgery, \\ ${ }^{2}$ Chris Hani Baragwanath Academic Hospital, \\ ${ }^{3}$ Charlotte Maxeke Johannesburg Academic Hospital, \\ ${ }^{4}$ University of the Witwatersrand.
}

Corresponding author: TE Luvhengo (thifhelimbilu.luvhengo@wits.ac.za)

\begin{abstract}
Background: Report of Hurthle cells following fine needle aspiration cytology from a thyroid nodule raises possibility of Hurthle cell carcinoma (HCC), which is a distinct entity and accounts for 3-10\% of thyroid malignancies.

Aim: To determine if there are demographic and histopathological features which may be used to differentiate HCC from Hurthle cell adenoma (HCA).

Methods: Histopathology records of patients who had thyroidectomy from January 2001 to October 2015 were reviewed. Data retrieved included indications for thyroidectomy, patients' demographics, histology and preoperative FNAC results.

Results: At total of 2641 records were reviewed of which 25.6\% (676/2641) were for neoplasms. 15.8\% (107/676) of the neoplasms were Hurthle cell neoplasms (HCNs) and 25.2\% (27/107) of HCNs were HCCs. 77.2\% (71/92) of HCAs and $77.8 \%(21 / 27)$ of HCCs were from female patients. Preoperative FNAC results were available for 54.2\% (58/107) and were suspicious of HCN in $12.1 \%$ (7/58). Average tumour size for HCCs and HCAs was $4.9+/-2.7 \mathrm{~cm}$ and $3.5+/-2.0$ $\mathrm{cm}$, respectively. The difference was statistically significant with a p-value of 0.016 . The risk of malignancy increased from $11.1 \%$ in HCNs less than $1 \mathrm{~cm}$ to $53.8 \%$ for tumours which were greater than $4 \mathrm{~cm}$ in diameter.

Conclusion: HCNs are more common in females. The likelihood of HCC rises as the size of the HCN increases. Malignancy rate exceeds $50 \%$ for $\mathrm{HCNs}$ which are greater than $4 \mathrm{~cm}$ in diameter.
\end{abstract}

Key words: Hurthle cell neoplasm, Hurthle cell carcinoma, FNA, tumour size

S Afr J Surg 2018;56(3) http://dx.doi.org/10.17159/2078-5151/2018/v56n3a2557

\section{Introduction}

Hurthle cell neoplasms (HCNs) include Hurthle cell carcinoma (HCC) which accounts for 5-10\% of thyroid malignancies. ${ }^{1}$ Hurthle cell carcinoma is different from follicular neoplasms morphologically and in clinical behaviour. ${ }^{2}$ Subtypes of HCC include classical, papillary and the medullary carcinoma variant. $^{3}$

Hurthle cells may be found in benign conditions such as multinodular goitre (MNG), thyroiditis and Graves' disease. ${ }^{3-6}$ Non-neoplastic Hurthle cells have also been reported in other malignant neoplasms of the thyroid gland such as follicular, papillary and medullary carcinoma. ${ }^{7}$

Diagnosis of $\mathrm{HCN}$ is only considered if more than $50-75 \%$ of fine needle aspiration cytology (FNAC) specimen from the lesion is composed of Hurthle cells. ${ }^{1}$ It is however not possible to diagnose HCC following FNAC as confirmation of HCC requires demonstration of evidence of invasion of the capsule, blood vessels or both. The Bethesda System for
Reporting Thyroid Cytopathology (Bethesda) is preferred for interpretation of FNAC result and guidance regarding further management. ${ }^{10}$ The Bethesda system categorises FNAC result into six categories: non-diagnostic (Bethesda I), benign (Bethesda II), atypia of undetermined significance or follicular lesion of undetermined significance (Bethesda III), follicular neoplasm or suspicious of follicular neoplasm (Bethesda IV), suspicious of malignancy (Bethesda V) and malignant (Bethesda VI). Recommended management of Bethesda III and IV thyroid lesions is either to repeat FNAC or to perform diagnostic lobectomy. At best FNAC from $\mathrm{HCN}$ is likely to show an indeterminate result, i.e. Bethesda III or IV lesion. ${ }^{8-10}$

Gender and age of patients, together with size of thyroid nodules have been used to try to predict the risk of malignancy in HCN. ${ }^{9,11-13}$ The aim of this study was to determine if there are demographic and histopathological features which may be used to differentiate HCC from Hurthle cell adenoma (HCA). 


\section{Materials and methods}

Histopathology records of all patients who had thyroidectomy from January 2001 to October 2015 at Charlotte Maxeke Johannesburg Academic Hospital and Chris Hani Baragwanath Academic Hospital were reviewed. Data retrieved included demographics and histopathology results. Histopathological data collected included tumour type, size, $\mathrm{HCN}$ subtypes and corresponding preoperative FNAC results. Demographic and histopathological data were entered into an Excel spreadsheet and analysed using Statistical Package for Social Sciences version 13.1 of 2015. Data for age and tumour size were presented as mean $+/$ - standard deviation. Fisher's exact test was used to compare categorical data and student's t-test for continuous data. The level of significance was set at p-value less than 0.05. Ethical approval was obtained from the Human Research Ethics Committee of the University of the Witwatersrand (M150944). Furthermore, permission to access records was obtained from the Department of Anatomical Pathology of the National Health Laboratory Services (NHLS) and Research Review Boards of Chris Hani Baragwanath Academic Hospital and Charlotte Maxeke Johannesburg Academic Hospital.

\section{Results}

A total of 2641 records were reviewed. $74.4 \%$ (1965/2641) of thyroidectomies yielded benign thyroid conditions and were excluded from further analysis.

The remaining $25.6 \%(676 / 2641)$ of thyroidectomies were for neoplasms. The mean age of patients who had thyroidectomy for neoplasms was $47.3 \pm 15.9$ years and $82.5 \%(558 / 676)$ of them were females. $71.2 \%(481 / 676)$ were malignant of which $62.0 \%(298 / 481)$ were papillary carcinomas and 5.6\% (27/481) HCCs (Table 1).

\begin{tabular}{lcc}
\multicolumn{3}{l}{ Table 1: Benign and malignant thyroid tumours } \\
\hline Pathological diagnosis & $\mathrm{n}=676$ & \\
Benign tumours ( $\mathrm{n}=195)$ & & Percent \\
Follicular adenoma & 115 & $59.0 \%$ \\
Hurthle cell adenoma & 80 & $41.0 \%$ \\
Malignant tumours ( $\mathrm{n}=481)$ & & \\
Papillary carcinoma & 298 & $62.0 \%$ \\
Follicular carcinoma & 82 & $17 \%$ \\
Medullary carcinoma & 40 & $8.3 \%$ \\
Hurthle cell carcinoma & 27 & $5.6 \%$ \\
Anaplastic carcinoma & 15 & $3.1 \%$ \\
Lymphoma & 6 & $1.3 \%$ \\
Metastatic carcinoma & 8 & $1.7 \%$ \\
unspecified carcinoma & 3 & $0.6 \%$ \\
Malignant teratoma of thyroid & 1 & $0.2 \%$ \\
Malignant solitary fibrous tumour & 1 & $0.2 \%$
\end{tabular}

A total of 107 patients had HCN of which $75.0 \%(80 / 107)$ were HCAs. $86.0 \%$ of patients who had HCNs were females. $88.7 \%(71 / 80)$ of HCAs and $77.8 \%(21 / 27)$ of HCCs were in female patients (Table 2).

\begin{tabular}{|c|c|c|c|}
\hline Parameter & $\begin{array}{l}\text { Hurthle cell } \\
\text { carcinoma }\end{array}$ & $\begin{array}{l}\text { Hurthle cell } \\
\text { adenoma }\end{array}$ & $p$-value \\
\hline No. of Patients & 27 & 80 & \\
\hline Males & $6(22.2 \%)$ & $9(11.3 \%)$ & \\
\hline Females & $21(77.8 \%)$ & $71(88.7 \%)$ & \\
\hline $\mathrm{M}: \mathrm{F}$ ratio & $1.0: 4.5$ & $1.0: 8.9$ & 0.156 \\
\hline \multicolumn{4}{|l|}{ Age groups } \\
\hline$<45$ years & $7(26 \%)$ & $29(36.3 \%)$ & \\
\hline $45-65$ years & $13(48 \%)$ & $31(38.8 \%)$ & \\
\hline$>65$ years & $6(22 \%)$ & $19(24.9 \%)$ & \\
\hline $\begin{array}{l}\text { Mean age }+/- \text { SD } \\
\text { (years) }\end{array}$ & $55.0+/-15.0$ & $52.3+/-15.6$ & 0.274 \\
\hline Age range & $32-84$ years & 23-95 years & \\
\hline $\begin{array}{l}\text { Mean tumour size } \\
(\mathrm{cm})+/ \text {-SD }\end{array}$ & $4.9+/-2.7$ & $3.5+/-2.0$ & 0.016 \\
\hline Size range & $0.8-10.0 \mathrm{~cm}$ & $0.2-9.0 \mathrm{~cm}$ & \\
\hline \multicolumn{4}{|l|}{ Size groups } \\
\hline$<1.0 \mathrm{~cm}$ & $3 / 26(11.1 \%)$ & $0 / 52(0 \%)$ & \\
\hline $1-4.0 \mathrm{~cm}$ & $9 / 26(33.3 \%)$ & $34 / 52(65.4 \%$ & \\
\hline$>4.0 \mathrm{~cm}$ & $14 / 26(52.8)$ & $18 / 52(34.6 \%)$ & \\
\hline
\end{tabular}

Preoperative FNAC results were available for 54.2\% (58/107) of the records of patients who had HCNs. In $1.7 \%$ (1/58) of the cases malignancy (Bethesda V) was suspected whereas $15.5 \%$ (9/58) showed Bethesda IV lesions (Table 3).

Table 3: Comparison of preoperative FNAC results and final histology in HCNs $(n=58)$

\begin{tabular}{lccc}
\hline Category & HCC & HCA & Total \\
\hline Non-diagnostic & 1 & 5 & 6 \\
Benign & 1 & 7 & 8 \\
Bethesda III & 1 & 4 & 5 \\
Bethesda IV & 9 & 22 & 31 \\
Suspicious of malignancy & 1 & 0 & 1 \\
Malignant & 0 & 7 & 7 \\
Total & $\mathbf{1 3}$ & $\mathbf{4 5}$ & $\mathbf{5 8}$ \\
HCC = Hurthle cell carcinoma, HCA = Hurthle cell adenoma
\end{tabular}

The average tumour size for HCCs and HCAs was 4.9 $\pm 2.7 \mathrm{~cm}$ and $3.5 \pm 2.0 \mathrm{~cm}$. The difference was statistically significant with a p-value of 0.016 . The probability of HCC in $\mathrm{HCN}$ increased as the size of the thyroid nodule got bigger and was $53.8 \%$ in nodules which were more than $4 \mathrm{~cm}$ in diameter. 


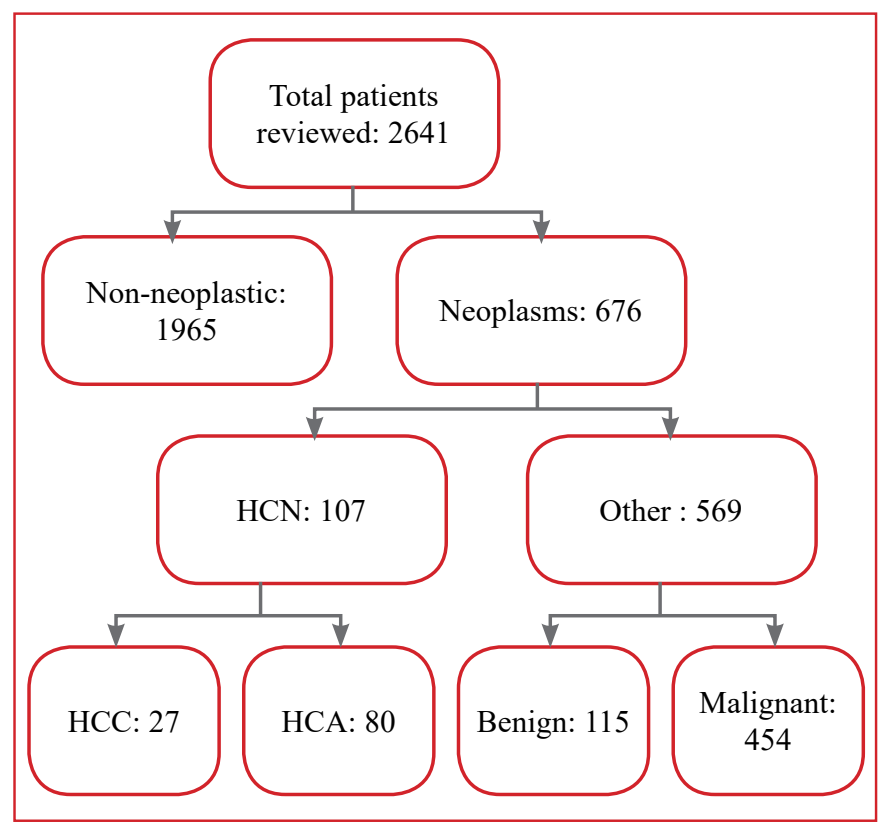

Figure 1. Breakdown of records of thyroidectomies based on underlying pathology

$66.7 \%(18 / 27)$ of the HCCs were follicular variant of HCC, whereas $11.1 \%(3 / 27)$ were papillary variant and $22.2 \%$ $(6 / 27)$ were pure HCC. $41.1 \%$ (44/107) of patients with HCN underwent total thyroidectomy and 50.5\% (54/107) had thyroid lobectomy. In $22.2 \%$ (6/27) of the patients, HCC was incidentally found following total thyroidectomy for MNG. Additionally, $18.5 \%$ (5/27) who had total thyroidectomy preoperative FNAC showed oxyphilic cell in the background of either MNG or Hashimoto's thyroiditis. 48.1\% (13/27) of patients with HCC had thyroid lobectomy as the initial procedure.

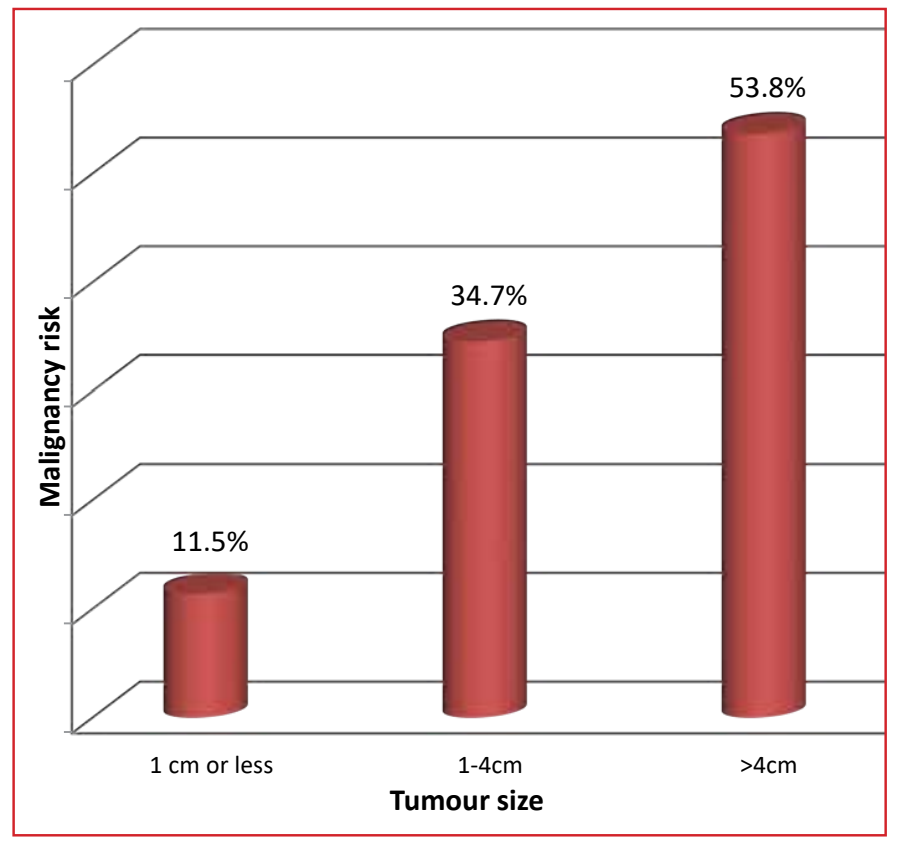

Figure 2. Relationship between $H C N$ size $(\mathrm{cm})$ and risk of malignancy (\%)
Capsular invasion was found in all HCCs whereas 59.3\% $(16 / 27)$ had both capsular and vascular invasion. Two patients who had completion thyroidectomy following diagnostic lobectomy which showed HCC were found to have HCA in the contralateral lobe.

\section{Discussion}

Over $70 \%$ of thyroidectomies in our setting are performed for non-neoplastic conditions. The incidence of HCN ranges from $3-10 \%$ of differentiated thyroid tumours. Several studies have shown the prevalence of malignant $\mathrm{HCC}$ ranging from $5-35 \% .{ }^{9,11,12,14}$ In the current study HCC represented 5.6\% of all differentiated thyroid cancers. The prevalence of malignancy amongst HCNs was $25.2 \%$, which is similar to what has been reported in literature. . $^{91,14}$

The diagnosis of Hurthle cell carcinoma is made if capsular and/or vascular invasion is/are demonstrated on histology. ${ }^{1}$ Several studies have shown that FNAC is a reliable test to diagnose HCNs. However, the distinction between benign and malignant $\mathrm{HCN}$ preoperatively is not possible. ${ }^{1,15}$ In this study we confirmed that FNAC cannot diagnose HCC. FNAC was also not useful for the diagnosis of HCA. Differentiating HCC from HCA or any other benign Hurthle cells bearing lesion is critical because appropriate definitive surgery such as total thyroidectomy may be indicated ab initio if HCC is highly likely..$^{11,13,14,16}$ Pisanu et al. ${ }^{14}$ would recommend consideration of total thyroidectomy for HCNs in which the likelihood of $\mathrm{HCC}$ is high.

Several clinical and histopathological features have been investigated to determine if they could be used to predict the likelihood of HCC in patients who have HCNs. These features include patient's age, gender, and tumour size. ${ }^{11,16,17}$ The majority of FNAC results when available in the current study were indeterminate, i.e. Bethesda III and IV. The rate of HCC of $29.7 \%$ in the indeterminate lesions from the current study is consistent with what is already known. ${ }^{12,13,18-20}$

No demographic parameter was found to be useful in predicting final diagnosis of HCC in the current study. The patient's gender is not useful for predicting malignancy in HCN. Patients who had HCC were older than the ones who had HCA but the difference was however not statistically significant. Carcangiu et al. ${ }^{19}$ and Lopez-Penabad et al.$^{20}$ found that HCC patients were older than patients who had HCA.

Several authors have reported that the risk of malignancy rises as the size of $\mathrm{HCN}$ increases. Straziser et al. ${ }^{14}$ reported that malignancy rate in patients with tumour size between 1 and $4 \mathrm{~cm}$ and greater than $4 \mathrm{~cm}$ were $20 \%$ and $40 \%$, respectively. Chen et al. ${ }^{13}$ also reported that $\mathrm{HCN}$ of the size of $1 \mathrm{~cm}$ or less had $17 \%$ chance of being malignant. Malignancy risk is $23 \%$ for tumours 1 to $4 \mathrm{~cm}$ in diameter and $65 \%$ for those which are $4 \mathrm{~cm}$ or larger. ${ }^{14}$

There is as yet no agreement as to the appropriate management of HCNs because of controversies involving diagnosis and biological behaviour. Some investigators recommended thyroid lobectomy as an initial surgical procedure, followed by completion thyroidectomy upon 
histological diagnosis of HCC. ${ }^{13,26}$ Others would recommend total thyroidectomy citing unpredictable biological behaviour, ${ }^{13}$ propensity for multifocality, ${ }^{16}$ and high likelihood of the malignancy. ${ }^{11,14}$

\section{Limitation of the study}

The study is an audit based on histopathology reports and therefore relies heavily on histology reports, and no other medical records have been reviewed. Some details were incomplete and information regarding subsequent management for Hurthle cell carcinoma in term of completion thyroidectomy and RAI ablation therapy were not looked into. In addition, the majority of the FNA results were not available for review. It could also not be established whether some of the patients who had diagnostic lobectomy which yielded HCC subsequently had completion thyroidectomy.

\section{Conclusion}

HCNs are more common in females and almost half of them are diagnosed following thyroidectomy performed for other thyroid pathologies. The likelihood of HCC rises as the size of $\mathrm{HCN}$ increases. Capsular invasion is reported more in HCCs than vascular invasion. Size of Hurthle cell neoplasm is the only parameter which is predictive of malignancy.

\section{Acknowledgement}

We sincerely appreciate the contributions of Professor Aylwyn Mannell during the protocol development phase.

\section{Conflict of interest}

All the authors have no conflict of interest to declare.

\section{REFERENCES}

1. Barnabei A, Ferreti E, Baldelli R, Procaccini A, Spriano G, Appetecchia M. Hurthle cell tumours of the thyroid. Personal experience and review of the literature. ACTA Otorhinolaryngo. 2009;29:305-11.

2. Ganly I, Ricarte Filho J, Eng S, et al. Genomic dissection of Hurthle cell carcinoma reveals a unique class of thyroid malignancy: J Clin Endocrinol Metab. 2013;98(5):E962-E972. doi: $10.1210 /$ jc. $2012-3539$

3. Montone KT, Baloch ZW, LiVolsi VA. The Thyroid Hurthle (Oncocytic) cell and its associated pathologic conditions. Arch Pathol Lab Med. 2008;132:1241-50.

4. Kauffmann P, Dejax C, de Latour M, Dauplat J. The meaning and predictivity of Hurthle cells in fine needle aspiration cytology for thyroid nodular disease. Journal of General Surgery doi:10.1016/j.ejso.2004.05.017

5. Alaedeen DI, Khiyami A, McHenry CR. Fine-needle aspiration biopsy specimen with a predominance of Hurthle cells: A dilemma in the management of nodular thyroid disease. Surgery. 2005;138:650-7. doi: 10.1016/j.surg.2005.06.047

6. Rossi ED, Martini M, Straccia P, et al. The cytologic category of oncocytic (Hurthle) cell neoplasm mostly includes lowrisk lesions: an institutional experience. Eur $\mathrm{J}$ Endocrinol. 2013;169:649-55. doi: 10.1007/s101200200012

7. Baloch ZW, LiVolsi VA. Fine needle aspiration cytology of papillary Hurthle cell carcinoma with lymphocytic stroma "Warthin-like tumor" of the thyroid. Endocr Pathol. 1998;9(1):317-23.

8. $\mathrm{Wu} \mathrm{HH}$, Clouse J, Ren R. Fine Needle aspiration cytology of Hurthle cell carcinoma of the thyroid. Diagn Cytopathol. 2008;36(3):149-54. doi: 10.1002/dc.20750

9. Lee KH, Shin JH, Ko ES, et al. Predictive factors of malignancy in patients with cytologically suspicious for Hurthle cell neoplasm of thyroid nodules. Int. J. Surg. 2013;11 (9):898-902. doi: 10.1016/j.ijsu.2013.07.010

10. Cibas ES, Ali SZ. The Bethesda System for reporting thyroid cytopathology; Am J Clin Pathol. 2009:132;658-65. doi: 10.1309/AJCPHLWM13JV4LA

11. Chen H, Nicol TL, Zelger MA, et al. Hurthle cell Neoplasms of the thyroid, are there factors predictive of malignancy? Ann Surg. 1998;227(4):542-6.

12. Strazisar B, Petric B, Sesek M, Zgajnar J, Hocevar M, Besic N. Predictive factors of carcinoma in 279 patients with Hurthle cell neoplasm of the thyroid gland. J Surg Oncol. 2010;101(7):5826. doi: $10.1002 /$ jso. 21526

13. Sippel RS, Elaraj DM, Khanafshar E, et al. Tumour size predicts malignant potential in Hurthle cell neoplasms of the thyroid. World J of Surgery. 2008;32(5);72-7.

14. Pisanu A. Oncocytic Cell Tumours of the Thyroid: Factors Predicting Malignancy and Influencing Prognosis, Treatment Decisions, and Outcomes, World J Surg. 2010;34:836-43.

15. Giorgadze T, Rossi ED, Fadda G, Gupta PK, LiVolsi VA, Baloch $Z$. Does the Fine-Needle Aspiration Diagnosis of "Hurthle cell neoplasm/ Follicular Neoplasm with Oncocytic Features" Denote Increased Risk of Malignancy? Diagn Cytopathol. 2004;31(5):307-12. doi: 10.1002/dc.20132

16. Zhang YW, Greenblatt DY, Repplinger D, et al. Older age and larger tumor sizepredict malignancy in Hurthle cell neoplasms of the thyroid. Ann Surg Oncol. 2008;15(10):2842. doi: 10.1245/s10434-008-0079-8

17. Kim TH, Lim JA, Ahn HY, et al. Tumour size and age predict the risk of malignancy in Hurthle cell neoplasm of the thyroid and can therefore guide the extent of initial thyroid surgery. Thyroid. 2010;20(11);1229-34. doi: 10.1089/thy.2009.0443

18. Pu RT, Yang J, Wasserman PG, Bhulya T, Griffith KA, Michael CW. Does Hurthle cell lesions/neoplasms predict malignancy more than follicular lesion on FNAC? Diagn Cytopathol. 2006;34(5):330-34. doi: 10.1002/dc.20440

19. Sorrenti S, Trimboli P, Catania A, Ulisse S, De Antoni E, D'Armiento M. Comparison of malignancy rate in thyroid nodules with cytology of indeterminate follicular or indeterminate Hurthle cell neoplasm. Thyroid. 2009;19(4):35560. doi: $10.1089 /$ thy. 2008.0338

20. Lopez-Penabad L, Chiu AC, Hoff AO, et al. Prognostic factors in patients with Hurthle cell neoplasms of the thyroid. Cancer. 2003;979(5):1186-94. doi: 10.1002/cncr.11176 